\title{
Nicotine Dependence of Electronic Cigarette, Dual Combustible and Electronic Cigarette Users
}

\author{
Jungun Lee* \\ Department of Family Medicine, Wonkwang University Sanbon Hospital, Wonkwang University School of Medicine, Gunpo, Korea
}

\section{See original paper on 197}

Although the prevalence of male adult tobacco smoking in South Korea has declined from $66.3 \%$ in 1998 to $36.7 \%$ in $2018,{ }^{1)}$ the prevalence of male adult electronic cigarette (EC) users in Korea increased from $2.0 \%$ in 2013 to $4.4 \%$ in 2017.2) Most EC users begin this habit assuming that it will assist them to cease smoking tobacco. ${ }^{3)}$ However, the main reason for the failure of smoking cessation in this group is associated with the level of nicotine dependence.

In this issue, Hwang et al. ${ }^{4}$ investigate nicotine dependence among exclusive combustible cigarette (CC) users, EC users, and dual users using a questionnaire and urine cotinine as a biochemical marker. Their study compares the difference between Heaviness of Smoking Index with urine cotinine.

Among those who currently smoke any type of cigarette: $89.4 \%, 1.4 \%$, and $9.2 \%$ were exclusive CC users, exclusive EC users, and dual users, respectively. Most exclusive CC users (about 69.2\%) were in their 30s to 50s, while most exclusive EC users (about 68.0\%) and dual users (about 68.4\%) were in their $20 \mathrm{~s}$ to $30 \mathrm{~s}$. The geometric mean of urine cotinine was highest among dual users $(1,356.4 \mathrm{ng} / \mathrm{mL})$, followed sequentially by exclusive CC users $(1,270.3 \mathrm{ng} / \mathrm{mL})$, and exclusive EC users $(867.7 \mathrm{ng} / \mathrm{mL})$. The differences in the average number of cigarettes smoked per day and Heaviness of Smoking Index scores were not statistically significant among the three groups. Although the urine cotinine analysis showed differences in nicotine dependence between the three groups, the differences were not clear in the survey questionnaire.

The authors rationalized this result due to the lack of a de- tailed questionnaire on EC use (e.g., EC use frequency, number of puffs, nicotine concentrations, vaporizing power, flavor, etc.).

Currently, EC technology is developing steadily, with future devices likely to deliver high-concentrations of nicotine more efficiently. Moreover, the number of new types of cigarettes, including ECs and "heat-not-burn" tobacco products, is increasing. ${ }^{5)}$ Developing new evaluation tools to measure nicotine dependence among dual and poly-users is essential.

In this study, $64.7 \%$ of dual users had tried to quit smoking for more than 24 hours in a day. Smoking cessation consultations for dual users need to be more strategic. New evaluation tools are needed to assess the amount of smoking and nicotine dependence of dual users or poly-users more efficiently.

\section{CONFLICT OF INTEREST}

No potential conflict of interest relevant to this article was reported.

\section{ORCID}

Jungun Lee: https://orcid.org/0000-0001-8580-1445

\section{REFERENCES}

1. Korea Disease Control and Prevention Agency. Korea National Health and Nutrition Examination Survey [Internet]. Cheongju: Korea Disease Control and Prevention Agency; 2016 [cited 2021 May 6]. Available from: https://knhanes.cdc. 
go.kr/knhanes/main.do.

2. Korea Health Promotion Institute. Current use status of electronic cigarettes in Korea [Internet]. Seoul: Korea Health Promotion Institute; 2018 [cited 2020 May 6]. Available from: https://nosmk.khealth.or.kr/nsk/ user $/$ extra/ntcc/nosmokeInfo/infoView/jsp/Page.do?siteMenuIdx= $62 \&$ c_gr $=1 \&$ c_id $=\&$ sort $=$ reg\&infoIdx $=6 \&$ postIdx $=17$ \&spage $=1 \&$ sR ow $=10$.

3. Gunter R, Szeto E, Jeong SH, Suh S, Waters AJ. Cigarette smoking in South Korea: a narrative review. Korean J Fam Med 2020;41:3-13.
4. Hwang JS, Lee CM, Lee K, Kim CY. Nicotine dependence evaluated by urinary cotinine and Heaviness of Smoking Index among smokers, vapers, and dual users: a cross-sectional study using the Korea National Health and Nutrition Examination Survey data. Korean J Fam Med 2020;42:197-203.

5. Lee CM. The impact of heated tobacco products on smoking cessation, tobacco use, and tobacco sales in South Korea. Korean J Fam Med 2020;41:273-81. 